\title{
EL ARTE COMO REALIDAD TRASFORMADA EN SU VERDAD. LA REHABILITACIÓN HERMENÉUTICA DE LA ESTÉTICA EN HANS-GEORG GADAMER
}

\author{
Antonio Gutiérrez-Pozo* \\ agpozo@us.es
}

RESUMO Este artigo pretende mostrar que a arte só tem relevância estética para Gadamer quando é libertada da estética. Os conceitos que definem a compreensão estética da arte, subjetivismo, experiência, objetivismo, baseiamse na noção central que caracteriza a estética: a diferenciação estética. A diferenciação estética implica uma diferença ontológica que isola o artístico e estabelece uma descontinuidade entre arte e realidade. A não diferenciação estética que Gadamer explica não só recupera a continuidade, mas afirma que a arte pertence à realidade na medida em que ela a transforma. Na arte cresce o ser do real no sentido de que a arte é a realidade mesma transformada em sua verdade.

Palavras-chave Gadamer, estética, arte, hermenêutica, diferenciação estética, não diferenciação estética, verdade.

\footnotetext{
ABSTRACT The aim of this article is to show that art has philosophical relevance for Gadamer solely insofar as it remains free from aesthetics. The concepts that define the aesthetic understanding of art, i.e. subjectivism, experience and objectivism, are built upon the central notion that characterizes aesthetics: the aesthetic differentiation. The aesthetic differentiation implies an
} 
ontological difference that isolates the artistic and establishes a discontinuity between art and reality. The aesthetic non-differentiation that Gadamer exposes does not only restore the continuity, but it also affirms that art belongs to reality insofar as it transforms it. In art grows the being of the real in the sense that art is the reality itself transformed in its own truth.

Keywords Gadamer, aesthetics, art, hermeneutic, aesthetic differentiation, aesthetic non-differentiation, truth.

\section{Introducción: la estética pertenece a la hermenéutica}

El propósito explícito de este artículo es explicar su título, pero esto equivale a desplegar todo el sentido contenido en una tesis que, no por casualidad, Gadamer presenta justo al final de la primera parte de Wahrheit und Methode dedicada al arte, y en la que se sintetiza todo el contenido esencial de su pensamiento sobre el arte: "La estética debe terminar (aufgehen) en la hermenéutica" (Gadamer, 1960, p. 170). En 1964 sostiene que "la hermenéutica incluye (einschließt) a la estética" (Gadamer, 1964, p. 5), lo que supone asegurar, insiste en una conversación de 1993, que "la estética concluye (aufgeht) de hecho en la hermenéutica" (Gadamer, 1993, p. 56). Esto significa que "la hermenéutica debe ser entendida de una manera tan amplia (umfassend) que incluya (einbezöge) toda la esfera del arte y su planteamiento (Fragestellung)" (Gadamer, 1960, p. 169). La condición de posibilidad de esta inclusión de la estética en la hermenéutica según Gadamer no es otra que el hecho de que "la experiencia del arte es una experiencia de sentido (Sinnerfahrung) y, como tal, es una realización del comprender (Leistung des Verstehens)" (Gadamer, 1993, p. 56). Para Gadamer, antes que producirnos vivencias estéticas, afectos placenteros o juicios de gusto, "la obra de arte nos dice algo (uns etwas sagt)", declara verdad, y, por ello, "resulta ser objeto de la hermenéutica (Gegenstand der Hermeneutik)" (Gadamer, 1964, p. 3). Por ser ante todo experiencia comprensiva del sentido más que experiencia sensitivo/subjetiva del gusto, pura experiencia estética, el arte pertenece esencialmente a la hermenéutica: "La experiencia de la obra de arte incluye comprensión (Verstehen), o sea, representa (darstellt) un fenómeno hermenéutico (hermeneutisches Phänomen)", y por eso, desde que "el comprender pertenece al encuentro (Begegnung) con la obra de arte misma" (Gadamer, 1960, p. 106), la estética según Gadamer debe ser rehabilitada hermenéuticamente. La inclusión de la estética en la hermenéutica no acaba con la autonomía (moderna) de la estética, sino que la redefine. Acaba más 
bien con la comprensión estética del ser de lo estético propia del s. XIX y elaborada desde presupuestos subjetivo/sensualistas y objetivistas, y base de aquella comprensión de la autonomía. Por tanto, la pertenencia de lo estético a lo hermenéutico supone una modificación en la comprensión del modo de ser de lo estético y un nuevo concepto de autonomía estética. Lo estético es en Gadamer hermenéutico, experiencia de sentido antes que experiencia estética, esto es, experiencia subjetiva, vivencial, sentimental y objetivista. Aclarar la pertenencia de la estética a la hermenéutica nos obliga a explicar qué significa que el arte sea experiencia hermenéutica o de sentido, es decir cómo la obra de arte nos dice algo. Desde este horizonte podemos desplegar el título de este trabajo. Sólo la superación de la estética en el sentido establecido en la modernidad -como algo definido por la noción de diferencia estética y delimitado por los conceptos de vivencia, subjetividad, sentimiento, gusto y objeto- y su 'hermeneutización', o sea, su comprensión rehabilitada desde la hermenéutica, sólo esto, es lo que permite una cierta relación arte-realidad según la cual el arte puede ser realidad trasformada en verdad.

\section{El valor hermenéutico del arte}

Wahrheit und Methode comienza planteando la pregunta por la verdad en el arte y efectivamente esta vinculación verdad/arte no es algo extraordinario ni novedoso, puesto que el propio Gadamer se ha referido a que ya establecieron ese nexo Hegel y -especialmente- Heidegger, cuyos pasos sigue y para quien en la obra de arte acontece la verdad (Vedder, 2000, p. 117). Lo que según Hammermeister ya "no es habitual es que una obra cuyo título es el problema de la verdad empiece con el arte" (Hammermeister, 1999, p. 78; Di Cesare, 2009, p. 59). Pero si Gadamer comienza su principal obra filosófica con la experiencia del arte como horizonte de la verdad se debe, sin duda, a que presupone que el arte no es un objeto más para la filosofía sino que tiene relevancia filosófica. Más aún: para Gadamer la experiencia del arte es una piedra de toque fundamental para determinar el alcance del propio saber filosófico: "Una de mis convicciones directivas (leitende Überzeugung) desde muy joven era que no se puede medir el valor o la falta de valor (Unwert) de un pensamiento filosófico sino en relación con la esencia de la obra de arte" (Gadamer, 1986, p. 419). Para entender la importancia del arte en la filosofía de Gadamer solo tenemos que reparar en lo que representa su hermenéutica respecto a las versiones anteriores de la misma. La hermenéutica en Schleiermacher y todavía en Dilthey, primero, era una teoría del método de las ciencias del espíritu, y segundo, ese método se basaba en el ideal objetivista/positivista científico-natural que considera que cualquier 
intervención del presente y de la subjetividad del intérprete contamina aquel ideal. Sólo con Gadamer, y tras la renovación heideggeriana, es sobre todo una experiencia renovada de la verdad en la que se incluye -como veremosla propia comprensión del intérprete (Grondin, 2001, p. 112; 2006, p. 61). Según Greisch, "la hermenéutica de Gadamer rompe con el metodologismo epistemológico de Dilthey" (Greisch, 2000a, p. 169). Gadamer subraya que, aunque no sea un método que pretende dominar los textos, la hermenéutica "trata acerca del conocimiento (Erkenntnis) y de la verdad" (Gadamer, 1960, p. 1), lo que significa que el método está lejos de ser el único modo de conocer y la única vía de acceso a la verdad. Frente al modelo cientificista, hay un modelo hermenéutico de la verdad, que Gadamer encuentra expresado en primer lugar en el arte.

De ahí que el título de la obra principal gadameriana haya producido tantos comentarios. Palmer p. e. sostuvo que se trataba de un título irónico, puesto que realmente el método no es en absoluto el camino para llegar a la verdad sino todo lo contrario, ya que la verdad se le escapa a la conciencia metódica (Palmer, 1969, p. 163). El ideal de método parte de dos presupuestos. El primero es que la verdad es un objeto que está ya ahí, en una presencia oculta, de modo que necesitamos del instrumento metódico para acceder a ella desde fuera, desde la distancia no interviniente del sujeto. De ahí se desprende como segundo presupuesto que la comprensión es una operación puramente teórica que se realiza desde fuera y al margen del objeto. Gadamer renueva la idea de comprensión en clave hermenéutica y ahora

el comprender no es tanto un método mediante el cual la conciencia cognoscente se volvería hacia el objeto (Gegenstand) elegido para lograr el conocimiento objetivo del mismo, como más bien el presupuesto de estar dentro (Darinstehen) de un acontecer de la tradición (Überlieferungsgeschehen). El comprender mismo se muestra como un acontecer (Geschehen) (Gadamer, 1960, p. 314).

Recordemos que el título original de Wahrheit und Methode iba a ser Comprensión y acontecimiento (Verstehen und Geschehen) (Gadamer, 1985a, p. 75). Contra el intelectualismo, comprender no es un proceso subjetivo intelectual y metódico frente a un objeto sino un acontecimiento que nos envuelve y del que formamos parte sin ser sus dueños: "El que comprende está siempre incluido en un acontecimiento en el que se hace valer (geltend macht) una plenitud de sentido (Sinnvolles)" (Gadamer, 1960, p. 494). Lejos de ser "una acción (Handlung) de la subjetividad", "un comportamiento subjetivo respecto de un objeto dado", la comprensión para Gadamer es "parte del acontecer de sentido (Teil des Sinngeschehens)", lo que significa que "pertenece al ser de lo que se comprende" 
(Gadamer, 1960, pp. 295, 170; 1965, p. 441). Al final comprobaremos el valor hermenéutico que posee esta pertenencia para la rehabilitación de la estética.

Decir que la comprensión forma parte del ser de lo que se comprende significa que no es mero método que acceda a la verdad como si ésta fuese un objeto exterior al que tuviera que conformarse, sino que la propia verdad del ser, la cosa misma en suma, se constituye en el comprender: "En tanto comprendemos estamos incluidos en un acontecer de la verdad (Wahrheitsgeschehen)" (Gadamer, 1960, p. 494). La comprensión es un acontecer, el acontecer de un encuentro entre la cosa y el sujeto, y en consecuencia solo en él es -se da- la verdad, el ser verdadero. Esto es lo que se desprende de esta conocida afirmación de Gadamer "el ser que puede ser comprendido es lenguaje (Sprache)" (Ibíd, p. 478). Esto significa que el ser se convierte en comprensión y, por tanto, en lenguaje, puesto que el ser, que siempre es comprendido, sólo es en el lenguaje. El ser que nos es, el ser que nos es comprensible, es lingüístico ya que, según Grondin, "todo lo que puede ser comprendido es un ser que se articula en el lenguaje" (Grondin, 2006, p. 63; Di Cesare, 2009, p. 199). Sólo en la experiencia/ acontecer del encuentro sujeto/objeto es la verdad hermenéutica, no como resultado de la metodología positivista. Pero el arte es para Gadamer el modelo de ese encuentro/experiencia, de esa verdad hermenéutica. Entonces, el título 'verdad y método', más que ironía, representa una contraposición: verdad y método se oponen, porque la verdad hermenéutica nunca puede ser 'objeto', ni objeto de un método. Sólo la verdad especial y particular de las ciencias naturales es un objeto controlable por el método. Lo que ha ocurrido en la modernidad es que una versión construida de la verdad, la científico-natural, se ha quedado en exclusiva con el dominio de la verdad. Por eso, es lógico que en la modernidad coincidan la estética y el auge del método científico-natural, y es que este último absorbe totalmente la verdad, de manera que entonces el arte queda separado radicalmente de ella y sólo le queda estetizarse, reducirse a fenómeno puramente subjetivo/vivencial sin valor de verdad. Por tanto, el triunfo del método científico y el nacimiento de la estética con la estetización del arte son dos hechos paralelos y complementarios. Di Cesare ha escrito que "la abstracción de la conciencia estética asegura el triunfo de la ciencia" (Di Cesare, 2009, p. 59). Pero contra el divorcio estético/positivista entre arte y verdad, Gadamer sostiene que "no se puede separar la pregunta por el arte de la pregunta por la verdad" (Gadamer, 1980, p. 203). Para Gadamer, según Grondin, "la obra de arte no proporciona exclusivamente goce estético sino que, ante todo, es encuentro con la verdad" (Grondin, 2006, p. 51).

Lo que hace Gadamer en cambio es recuperar un concepto más originario de la verdad como experiencia o acontecimiento. Esta verdad no es metódica 
sino hermenéutica. Ahora se entiende mejor el valor hermenéutico del arte, puesto que una vez que la hermenéutica ha experimentado ese giro radical no es casualidad que lo primero que trate Gadamer en Wahrheit und Methode sea la experiencia de verdad del arte. Ello se debe a que Gadamer reconoce que "se puede obtener una nueva experiencia de la verdad desde el arte" y de carácter hermenéutico (Di Cesare, 2009, p. 59). Frente al modelo de conocimiento y verdad objetivista y metódico establecido por las ciencias naturales, la especial relevancia filosófica que tiene el arte para Gadamer se debe a que aporta un modelo diferente y hermenéutico. La clave hermenéutica de este nuevo modelo de verdad y conocimiento propio del arte es que, frente al metodológico, en la experiencia del arte el sujeto está dentro de ella, sin distancia, sin ser dueño sino dominado por ella. ${ }^{1}$ El hecho de que el arte para Gadamer no sea algo meramente estético/subjetivo sino una forma peculiar de comprensión ajena al modelo científico-natural, le obliga a aclarar el modo de ser del arte, para comprender su comprender (Simms, 2015, p. 57). Para hacerlo tiene que enfrentarse a la estética, que ha apartado al arte del conocimiento y de la verdad, porque sólo rompiendo con ella podrá reintegrarlos.

\section{La estética moderna: subjetivismo vivencialista y objetivismo}

Gadamer advierte que para legitimar la experiencia de verdad en el arte es necesario apartarlo de la estética. La comprensión crítica de la estética que formula Gadamer sigue la que ya planteó Heidegger con la diferencia de que Gadamer usa el término 'estética' en un sentido más amplio porque considera que se puede entender el modo de ser de lo estético en clave ya hermenéutica y no estética, apartándose entonces de la condenable comprensión subjetivista dominante en la modernidad. Gadamer entonces emplea el mismo vocablo 'estética' indistintamente tanto en sentido estricto y restringido, que sería el concepto moderno que él mismo denuncia, como en sentido neutro y amplio, que es el que le permite introducir su innovación crítica. Por tanto, abre la posibilidad de una desestetización de la estética y su rehabilitación hermenéutica, es decir, confía en obtener un concepto no estético de la estética, no subjetivista, sino más bien hermenéutico. Sólo así puede incluir la estética en la hermenéutica. Heidegger en cambio siempre usó el término 'estética' en sentido estricto, o sea, en el rechazable sentido subjetivista. Para poder entender la renovación hermenéutica de la estética que acomete Gadamer es necesario exponer las

1 Esto permite a Gadamer establecer un nexo entre arte y juego, puesto que la experiencia lúdica prefigura la experiencia artística (Ricoeur, 1986, p. 59; Greisch, 2000b; Vilhauer, pp. 25-37). 
deficiencias de la comprensión estética del arte. Junto a Heidegger, Gadamer comienza por la crítica de la estética moderna.

Siguiendo a Heidegger y Gadamer podemos afirmar que la comprensión estética del arte está constituida por dos tesis básicas e indisolublemente unidas: por una parte, el subjetivismo vivencialista y la ausencia de relevancia cognoscitiva que le acompaña y, por otra, el objetivismo en el sentido del carácter de objeto de la obra de arte. Estas dos tesis se fundan a su vez sobre otra, la 'diferencia estética', que es la condición de posibilidad fundamental del planteamiento estético según Gadamer. Analizar estos tres rasgos equivale a realizar una anatomía de la estética moderna. Heidegger considera que, junto a otros fenómenos, "una tercera manifestación (Erscheinung) igualmente esencial de la Edad Moderna es el proceso que incluye al arte en el campo de la estética" (Heidegger, 1938, p. 75). La estética moderna, la estética en sentido estricto, es consecuencia de la metafísica moderna de la subjetividad que consiste, en clave cartesiana, en la reducción de todo lo existente al sujeto como fundamento absoluto: "La conciencia estética es consecuencia de la subjetivización del pensamiento desde Descartes" (Palmer, 1969, p. 167). En la modernidad "el ser humano y su libre saber (freies Wissen) sobre sí mismo y su posición entre los entes se convierte en el lugar de la decisión (Ort der Entscheidung) acerca de cómo experimentar, determinar y configurar (gestalten) el ente" (Heidegger, 1936-37, p. 81). El 'yo' es ámbito de verdad y todo se mide desde él. Por tanto, 'estética' es aquella comprensión del arte que lo entiende desde el sujeto humano reducido a sus experiencias sentimentales: "La estética considera la obra de arte como un objeto, a saber, como el objeto de la $\alpha \grave{l} \sigma \theta \eta \sigma l \varsigma$, de la percepción sensible en sentido amplio. Hoy se llama a esta percepción (Vernehmen) vivencia (Erleben)" (Heidegger, 1935-36, p. 67). La estética entonces es "aquella meditación (Besinnung) sobre el arte en la que la relación sentimental (fühlende Verhältnis) del ser humano con lo bello representado en él suministra el ámbito decisivo (maßgebenden Bereich) de determinación y fundamentación, su principio y su fin", de donde deduce que es "el modo de preguntar por el arte y lo bello a partir del estado sentimental (Gefühlzustand) de los receptores (Genießenden) y productores (Erzeugenden)" (Heidegger, 1936-37, pp. 76s). Lo que encuentra Heidegger tras la estética es un presupuesto metafísico de carácter humanista, la antropologización del ente, la "primacía del ser humano como sujeto (Subjektum) [...] y del ser humano como vida (Leben)", y por esa razón para la estética "la obra de arte se convierte en objeto de la vivencia (Gegenstand des Erlebens) y el arte se vuelve expresión (Ausdruck) de la vida del ser humano" (Heidegger, 1938-39, p. $34 ; 1938$, p. 75). La estética considera el arte estéticamente, lo estetiza, o 
sea, lo entiende "desde la expresión y la impresión (Eindruck), la obra como expresión (Expression) y la impresión (Impression) como vivencia (Erlebnis)" (Heidegger, 1951-52, p. 132). Entendida como subjetivismo vivencialista, la estética supone "una humanización (Vermenschung) del arte" (Heidegger, 193839, p. 37). Comprender el arte quiere decir para la estética analizar las vivencias humanas en que se da, sean receptivas, creativas, culturales o -cuando el arte deviene sector industrial- comerciales: "El modo en el que el ser humano vive el arte debe darnos información sobre su esencia" (Heidegger, 1935-36, p. 67).

Si la estética reduce el arte a experiencia sentimental subjetiva, a vivencia, niega su valor de conocimiento y lo aparta de la verdad. Kant expone esta carencia de relevancia cognoscitiva del arte: "El juicio de gusto (Geschmacksurteil) no es un juicio de conocimiento (Erkenntnisurteil), por tanto no es lógico sino estético, entendiendo por ello aquel cuyo fundamento de determinación sólo puede ser lo subjetivo" (Kant, 1990, §1, p. 39). El juicio estético de gusto no proporciona conocimiento ni tiene que ver con la verdad, pues mediante él "nada es designado (bezeichnet) en el objeto" sino que expresa "cómo el sujeto se siente (fühlt) en tanto es afectado (affiziert) por la representación (Vorstellung)" (Ibid., p. 40). En tanto que nada dice del objeto y sólo se refiere a los estados sentimentales del sujeto, "la facultad del juicio estético (ästhetische Urteilskraft) nada contribuye al conocimiento de sus objetos" (Kant, 1990, Einleitung, p. 32). Gadamer asume que es imposible reconocerle al arte su calado cognoscitivo "cuando, con Kant, se mide la verdad del conocimiento desde el concepto de conocimiento de la ciencia y el concepto de realidad de la ciencia natural" (Gadamer, 1960, p. 103). La estetización del arte es consecuencia lógica del positivismo que reduce el conocer al de la ciencia natural. Contra esta concepción estética, Gadamer considera no sólo que "el arte es conocimiento", sino que "la experiencia de la obra de arte hace participable este conocimiento" (Ibíd.). Gadamer comprende que la única forma de legitimar el poder cognoscitivo del arte es ampliar el concepto de conocimiento para que no se lo apropie el método de la ciencia natural y poder afirmar que

la experiencia del arte es un modo de conocimiento propio [...] diferente de todo conocimiento racional moral (sittlichen Vernunfterkenntnis) y, en general, de todo conocimiento conceptual (begrifflichen Erkenntnis), pero conocimiento a pesar de todo, es decir, mediación (Vermittlung) de la verdad,

de manera que entonces "se da en la experiencia (Erfahrung) del arte una pretensión (Anspruch) de verdad, diferente de la de la ciencia, pero no inferior" (Ibíd.). Esta intrascendencia cognoscitiva de la comprensión estética concluye en un formalismo estético, en la falta de atención al contenido, pues la forma afecta 
a la vivencia, mientras que el contenido se refiere al intelecto. El vivencialismo o subjetivismo de la estética sólo podía conectar con el formalismo: "Cuando se habla de experiencia estética habitualmente se supone que lo importante no son los contenidos sino más bien la forma, o sea, sólo la calidad de la configuración (Gestaltungsqualität) de una obra de arte. De esta opinión vive el formalismo (Formalismus) de la estética" (Gadamer, 1993, p. 55). La comprensión subjetivista del arte propia de la estética, que reduce el arte a vivencia humana, supone como tesis complementaria de índole objetivista que eso reducido a cosa de la vivencia es objeto: "La obra de arte es dispuesta (angesetzt) como objeto (Objekt) para un sujeto (Subjekt). La relación sujetoobjeto es decisiva para su consideración, en concreto la relación sentimental (fühlende). La obra deviene objeto (Gegenstand) en su lado vuelto hacia la vivencia" (Heidegger, 1936-37, p. 76). Para la estética, subraya Heidegger, "la obra de arte, en su ámbito decisivo, deviene objeto del sentir (Fühlens) y del representar (Vorstellens)" (Heidegger, 1953-54, p. 131). No obstante, Heidegger destaca que en la estructura estética sujeto/objeto el peso último corresponde al sujeto, pues ya que "la determinación de lo artístico se hace en relación a la creatividad (Schöpferische) y la maestría (Meisterschaft)", entonces "el discurso acerca de lo artístico (Künstlerischen) muestra siempre la primacía del artista como sujeto que permanece referido a la obra como su objeto" (Ibid., p. 132). ${ }^{2}$

Pero para Heidegger la estética, al reducir el arte a la vivencia y considerarlo expresión humana, lo malentiende, no experimenta su verdad, pues "tal vez sea la vivencia el elemento en el que el arte muere" (Heidegger, 1935-36, p. 67). Para la estética, escribe Heidegger, "el arte puede ser representado como un sector empresarial de la cultura. Pero entonces no se experimenta nada de su esencia" (Heidegger, 1953a, p. 39). En la estética, "el arte es sometido a una utilización cultural y es esencialmente desconocido" (Heidegger, 1936-38, p. 117). Según Heidegger, la estética ignora la auténtica realidad del arte, que no consiste en vivencia, en cosa humana, sino en una experiencia ontológica, en el "ponerse en obra de la verdad de lo ente (das Sich-ins-Werk-Setzen der Wahrheit des Seienden)" (Heidegger, 1935-36, p. 21). Decir que el arte es un

2 Para Heidegger la estetización del arte permite tanto la existencia del museo y otras instalaciones culturales modernas, como su comercialización, porque "sólo cuando la obra de arte se ha convertido en objeto es susceptible de ser expuesta (ausstellungs) y de estar en el museo [...] y de ser valorada y tasada (bewert-und abschätzbar)" (Heidegger, 1953-54, pp. 131s). Heidegger muestra que la calidad de lo artístico, un valor estético, es clave en la experiencia actual del arte y en su tratamiento comercial. Esto es posible porque la traslación del arte a la vivencia y su conversión en objeto permiten su control y manipulación, pues la "formación vivencial (Erlebnisschulung) pertenece a la esencia de la seguridad manipuladora (machenschaftlichen Sicherheit) del ente en total" (Heidegger, 1938-39, p. 33). La comprensión estética del arte también presupone, como la metafísica que le subyace, la maquinización y dominio de lo existente. 
"poner-en-obra de la verdad (del ser) (Ins-Werk-Setzen der Wahrheit (des Seyns))" significa decir que la obra de arte es un ámbito de verdad, lugar originario de la presencia del ser de las cosas, o sea, "claro del ser (Lichtung des Seyns)" (Heidegger, 1938-39, pp. 35, 37). ${ }^{3}$ La verdadera índole ontológica y no estética del arte consiste en traer algo al ser desde el no-ser, en desvelarlo: "Para en general dejar surgir (erstehen zu lassen) el ente en sí, debe estar el arte, que pone (setzt) en su obra la verdad" (Heidegger, 1936-38), p. 243). A diferencia de lo que "es el arte para la estética, representación de lo bello (Darstellung des Schönen) en el sentido de lo que agrada en tanto agradable (Gefällige)", Heidegger asegura que "el arte es la apertura (Eröffnung) del ser del ente" (Heidegger, 1935, p. 140). Antes de ser pensado estéticamente, el mundo griego experimentó el arte según Heidegger en su genuina naturaleza:

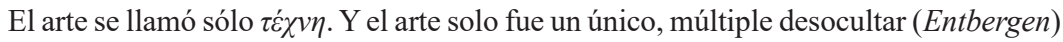
[...] Las artes no proceden de lo artístico (Artistischen). Las obras de arte no fueron estéticamente gozadas. El arte no era un sector de la creación cultural [...] era un

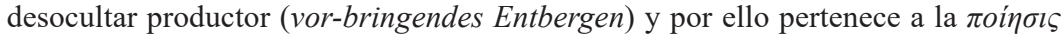
(Heidegger, 1953b, p. 35). ${ }^{4}$

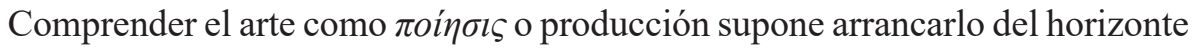

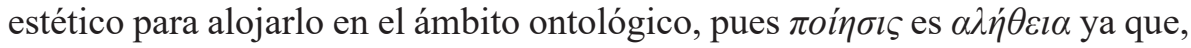
como $\varphi v ́ \sigma \iota \varsigma$, desoculta, hace surgir, pasar del no-ser al ser. Lo que se pone en obra en el arte, lo que se desvela, es la verdad de lo existente, de modo que en el arte según Heidegger "lo real le regala al ser humano, cada vez de un modo nuevo, su hasta ahora oculto resplandor (verborgenen Glanz)" (Heidegger, 1953a, p. 39). Contra el antropologismo estético y del humanismo metafísico, Heidegger advierte que esta operación desveladora del arte "ha perdido su referencia a la cultura y se revela aquí sólo como un acontecimiento del ser (Ereignis des Seyns)" (Heidegger, 1936-38, p. 505).

3 Heidegger sostiene que "llamamos claro (Lichtung) a esa apertura (Offenheit) que hace posible que algo aparezca y se muestre (Scheinenlassen und Zeigen)" (Heidegger, 1964, p. 80).

4 La estética como estética del genio ha intentado apropiarse de este lado productivo del arte, pues el imperio de la vivencia no se limita al espectador sino también al creador. Contra esta acentuación del lado subjetivo de la creación de la obra mediante el concepto estético de genio, que desaparece en Heidegger, éste afirma que, una vez aclarado que "efectuar (er-wirken) significa aqui llevar a la obra (ins Werk bringen), "la obra de arte no es primero obra en tanto es efectuada (gewirkt), hecha (gemacht), sino porque efectúa (er-wirkt) el ser en un ente", de manera que el efectuar artístico, en vez de ser considerado subjetivamente como actividad

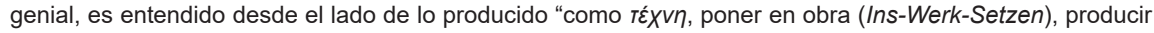
que abre (eröffnendes Er-wirken) el ser en el ente" (Heidegger, 1935, p. 168). 


\section{La diferencia estético/ontológica como esencia de la estética}

Gadamer asume la descripción heideggeriana de los dos rasgos fundamentales la estética, su comprensión subjetivo/objetiva del arte:

La obra de arte sólo es una forma vacía (Leerform), un simple punto crucial en la posible pluralidad de las vivencias estéticas (ästhetischen Erlebnissen), sólo en la cual está el objeto estético. La consecuencia necesaria de la estética vivencial (Erlebnisästhetik) es la absoluta discontinuidad, la desintegración de la unidad del objeto estético en la multiplicidad de las vivencias (Gadamer, 1960, p. 101).

La estética reduce la obra a objeto estético, pero el objeto estético no es un hecho, sólo 'es' en el río de vivencias. Como para Heidegger, también para Gadamer la estética es enemiga del arte y por ello asegura que

las grandes épocas de la historia del arte fueron aquellas en las que, sin conciencia estética (ästhetische Bewußtsein) y sin nuestro concepto de 'arte', todos estaban rodeados de configuraciones (Gestaltungen) cuya función vital religiosa o profana era comprensible para todos y nadie gozaba sólo estéticamente (Ibíd., p. 87).

En consecuencia, Gadamer considera que "para hacer justicia al arte la estética debe superarse (hinausgehen) a sí misma y abandonar la pureza de lo estético (Reinheit des Ästhetischen)", es decir, debe desestetizarse: "Hemos comenzado con la crítica de la conciencia estética" (Ibíd., pp. 98, 105). Ahora bien, superar la estética implica superar la tesis de la diferencia estética, que es el fundamento no sólo de esos dos rasgos sino de la propia estética según Gadamer. La desestetización de la estética depende de que se renuncie a la 'diferencia estética', porque sólo entonces lo estético se podrá rehabilitar superándose a sí mismo, o sea, superando la pureza de lo estético, e interpretando su modo de ser hermenéuticamente, no estéticamente. La estética, cuya fundación principal localiza Gadamer en Schiller (Ibíd., p. 90), se asienta sobre una tesis ontológica: entiende lo estético como modificación de lo real, o sea, como un modo de ser modificado a partir de la realidad, como irrealidad, ilusión o apariencia (bella) frente a lo real verdadero. El arte es algo estético, algo por tanto que pertenece a este orbe de irrealidad y apariencia. Lo que hace la estética es una 'diferencia estética' (ästhetische Unterscheidung), esto es, diferenciar lo estético, su modo de ser, que es irrealidad o virtualidad, del modo de ser de lo real, que es realidad (Ibíd., p. 91). La diferencia estética, centro de la estética, equivale a una diferencia ontológica entre la apariencia o irrealidad, que le corresponde a lo estético, y la realidad. La estética se funda sobre la diferencia entre la realidad y lo puro estético, ámbito ontológicamente diferente de lo real donde se aloja el arte como una modificación del ser de la realidad, o sea, con 
un modo de ser esencialmente distinto al de lo real, como irrealidad, apariencia o ilusión: "El arte de la 'apariencia bella' (schönen Scheins) se opone a la realidad" (Ibíd., p. 90). De ahí que Di Cesare haya señalado que mediante la diferencia estética el arte deviene algo irreal (entwirklicht) (Di Cesare, 2009, p. 57). Nuestra tesis es que el vivencialismo que caracteriza a la estética es también la clave de fondo de la diferencia estética, puesto que lo que permite aislar lo estético en su pureza y establecer la discontinuidad ontológica entre arte y realidad, es precisamente localizarlo en el plano de la vivencia, en esa dimensión subjetiva aparte de lo real. La existencia de la estética presupone esta contraposición, esta "ruptura (Scheidung) entre la apariencia bella y la más áspera realidad (rauher Wirklichkeit)" (Ibíd., p. 95). De ahí que, según destaca Gadamer, el nacimiento de la estética, que "es una invención muy tardía" pues "no surgió hasta el s. XVIII" y "provocada por el racionalismo moderno", "coincide -lo que es significativo- con la aparición del sentido eminente del arte separado del contexto de la práctica productiva" (Gadamer, 1974, p. 107). No hay estética filosófica hasta que no existe una comprensión estética del arte que lo desconecta de la realidad. El racionalismo, al convertir la razón conceptual en órgano absoluto del conocimiento, aparta al arte de la verdad y del conocer, y produce la estética y la estetización del arte.

La diferencia estética consiste según Gadamer en una abstracción estética puesto que, como "sólo elige la calidad estética como tal", lo formal-estético, lo que hace es abstraer lo estético y apartarlo (diferenciarlo) en su pureza estética del resto de lo real: "La conciencia estética es una abstracción (Abstraktion) (que) deja ver y ser para sí lo que es una obra de arte pura" (Gadamer, 1960, pp. 87, 91). La abstracción estética, que "se ejecuta (vollzieht) en la autoconciencia de la vivencia estética", aísla lo puramente estético de la obra y lo pone al margen de elementos no estéticos, como su contenido o finalidad: "Aquello hacia lo que está dirigida la vivencia estética debe ser la auténtica obra, que prescinde (absieht) de los momentos extraestéticos que le son inherentes: fin (Zweck), función, significado de contenido (Inhaltsbedeutung)" (Ibíd., p. 91). A la diferencia estética se debe la separación que realiza la conciencia estética entre la obra de arte y su mundo originario:

Lo que llamamos obra de arte y vivimos estéticamente se basa en una producción de la abstracción. La obra se manifiesta como pura obra de arte al prescindir (abgesehen) de todo aquello en lo que arraiga como su originario contexto vital (ursprünglichen Lebenszusammenhang), de toda función religiosa o profana, de todo sobre lo que se erigió y tuvo significado (Ibid.). 
La obra de arte, añade Gadamer, "mediante la diferencia estética por la que pertenece a la conciencia estética, pierde su lugar y el mundo al que pertenece" (Ibíd., p. 93). Este aislamiento y abstracción de lo estético, que oculta su mundo vital de procedencia, hace posible la biblioteca, el museo o la sala de conciertos: "La abstracción estética [...] separa la obra de arte de su lugar histórico en el espacio y en el tiempo y la traslada a la intemporalidad del museo" (Gadamer, 1960, p. 92; 1958, p. 11). El museo como símbolo de las instalaciones estéticas modernas representa la materialización de la conciencia estética, la consumación efectiva de la diferencia estética. La abstracción estética supone un formalismo estético. Así, aunque aquellos elementos de contenido puedan ser muy significativos, según Gadamer "la esencia artística de la obra tiene que poder distinguirse de todo esto", pues "lo que define a la conciencia estética es que lleva a cabo la diferencia entre lo estéticamente intencionado (ästhetisch Gemeinten) y todo lo extraestético (Außer-Ästhetischen)", de modo que "diferencia la calidad estética de una obra de todos los momentos de contenido que nos determinan a tomar posiciones de contenido, morales o religiosas, y sólo se refiere (meint) a la obra en su ser estético" (Gadamer, 1960, p. 91). Con Gadamer, Palmer sostiene que "la visión estética del arte implica aislarlo, no atender a su contenido", y en consecuencia "sólo vale el gozo perceptivo para medir y valorar la obra arte" (Palmer, 1969, p. 167), o sea, lo que afecta a la vivencia. Como anticipamos, formalismo, vivencialismo y estética están esencialmente conectados. Contra el formalismo estético, confiesa Gadamer, "no reclamo una estética del contenido según el modelo hegeliano", que disuelve lo artístico reduciéndolo al concepto, sino que "sostengo que una obra de arte, gracias a su calidad configuradora (Gestaltungsqualität), nos dice algo" (Gadamer, 1993, p. 55). Lo formal-artístico ni concluye en formalismo, ni es suplantado por conceptos, sino que es declaración inagotable de verdad.

\section{El carácter ontológico de la no-diferencia estética. La estética de la pertenencia}

Hay que plantear una "crítica de la abstracción de la conciencia estética" porque el modelo de la 'diferencia estética', según Gadamer, es una forma errónea de entender lo estético: "Estan en el error todos los intentos de pensar el modo de ser de lo estético a partir de la experiencia de la realidad y de entenderlo como una modificación de la misma" (Gadamer, 1960, pp. 94, 89). Entender lo estético como una modificación de lo real que abre una discontinuidad ontológica entre realidad y estética (irreal, aparente) implica que entonces lo estético ni es el 'auténtico ser', que sería lo real, ni puede haber en él verdad. 
Esto es un error porque según Gadamer ocurre más bien lo contrario: “Todos estos conceptos de imitación (Nachahmung), apariencia (Schein), desrealización (Entwirklichung), ilusión (Illusion), magia, sueño, presuponen la relación a un ser auténtico (eigentliches Sein) del que sería diferente el ser estético", pero "la experiencia estética no piensa desde esa relación y más bien ve la auténtica verdad en lo que ella misma experimenta (erfährt)" (Ibíd., p. 89). La estética, basada en el esquema de la diferencia estética, presupone la adscripción en exclusiva de la verdad y el conocimiento a la ciencia, que trata la realidad, mientras que el arte, limitado a la apariencia bella, es despojado de cualquier alcance cognoscitivo:

La relegación de la determinación ontológica de lo estético al concepto de la apariencia estética tiene su fundamento teórico en el dominio (Herrschaft) del modelo de conocimiento científico-natural que desacredita todas las posibilidades de conocimiento que haya fuera de esa nueva metododología (Ibid., pp. 89s).

Para que la experiencia estética vea la verdad en lo que ella misma experimenta hay que disolver la diferencia estética. El arte sólo puede ser declaración de verdad previa desestetización del modo de ser de lo estética mediante su rehabilitación hermenéutica. Mientras lo estético y el arte eran situados por la estética en un plano ontológico distinto al de la realidad, lo irreal o aparente, no podía localizarse en ellos la verdad de lo real. Para lograrlo hay que acabar con la ruptura entre arte y realidad. Sólo la disolución de esa discontinuidad permite al arte ser la realidad misma trasformada en su verdad. Por eso, escribe Gadamer, "contraponemos a la diferencia estética-verdadero constituyente de la conciencia estética-la no-diferencia estética (ästhetische Nichtunterscheidung)" (Ibid., p. 122).

Esta no-diferencia arte/realidad significa que la imagen estética del arte pertenece a lo real. Contra la diferencia que supone el vivencialismo al situar lo estético en el plano subjetivo/vivencial, al margen de lo real, Gadamer restablece la continuidad -identidad- entre estética (arte) y realidad. Pero acabar con la ruptura no significa afirmar que no sean distintos arte y realidad. Hay identidad, continuidad, acaba con la discontinuidad ontológica, pero para Gadamer sigue habiendo diferencia arte-realidad. Hay diferencia en la continuidad. Se trata de lo que Gadamer ha llamado identidad hermenéutica (hermeneutische Identität) (Gadamer, 1981, p. 250; 1974, p. 116), es decir, una identidad que contiene la diferencia como su propia esencia y que, por tanto, no se realiza sino mediante la diferencia. Esta identidad hermenéutica supone, pues, "la crítica a un concepto de identidad que no encierre en sí mismo la diferencia (Differenz)" (Gadamer, 1992, p. 418). Di Cesare ha obervado que "la 
nueva identidad es una identidad que sólo se forma en la diferencia. Por eso, muestra la diferencia como imprescindible para la identidad" (Di Cesare, 2009, p. 75). Este concepto de identidad hermenéutica permite a Gadamer asegurar que "aferrarse a la identidad de sentido (Sinnidentität) de un texto ni es una recaída en el superado platonismo de una estética clasicista, ni es atascarse en la metafísica", tal como sostienen críticamente contra la hermenéutica el deconstructivismo (Dekonstruktivismus) de Derrida y la estética de la recepción de Jauss, y no lo es porque la identidad hermenéutica pone a Gadamer al margen del sustancialismo al "conciliar la diferencia del comprender con la unidad de la obra" (Gadamer, 1985b, p. 7). No se ha percibido que, al lado de esa identidad, hay también una diferencia hermenéutica en Gadamer, que es aquella que sólo "está en la identidad, y en caso contrario la identidad no sería identidad" (Gadamer, 1987, p. 137). Si la identidad hermenéutica protegía a Gadamer de recaer en la metafísica y su identidad sustancial, esta noción de diferencia hermenéutica, con la copertenencia esencial entre identidad y diferencia que supone, lo salva de abrazar el nihilismo hemenéutico (hermeneutische Nihilismus) que, a su juicio, se desprende de la tesis derridiana de la différance, según la cual sólo hay 'diferir', o sea, textos, interpretaciones, diferencias, sin identidad que las limite, puesto que "no hay fuera de texto (Il n'y a pas de hors-texte)" (Derrida, 1967, pp. 92, 227; Gadamer, 1960, p. 100; 1958, p. 15). Al introducir la diferencia, Gadamer, que afirma la continuidad, evita la identificación total, o sea, coloca lo artístico en lo real sin supeditarlo y reducirlo al mundo histórico/vital donde es producido. Gadamer impide que, tras negar la separación radical que establecía la estética, abracemos ahora la continuidad total sin diferencia entre el ámbito estético y el real, de modo que el arte pudiera ser explicado exclusivamente a partir de su contexto de realidad, sin atender a la declaración que es la obra de arte con independencia de su realidad histórica-vital de origen: "La realidad de la obra de arte y su fuerza declarativa (Aussagekraft) no se dejan limitar al horizonte histórico originario", sino que es "expresión de una verdad que en absoluto coincide con lo que el autor espiritual (geistige Urheber) de la obra pensó realmente en ella" (Gadamer, 1964, p. 1). Cuando Gadamer afirma que "no basta limitarse a la mens auctoris" quiere decir que no se puede reducir la obra de arte a su mundo real de origen, porque "el lenguaje del arte se refiere al exceso de sentido (Sinnüberschuß) que descansa en la propia obra" (Ibíd., p. 7). $\mathrm{Al}$ acercarnos al arte con conciencia histórica, "sabemos que la Novena Sinfonía de Beethoven surgió en un determinado contexto histórico-musical e históricoespiritual y que sólo desde ese contexto es comprensible históricamente", pero Gadamer precisa que la conciencia de la identidad hermenéutica nos enseña que "la Novena Sinfonía significa para nuestro comprender más que un sistema 
de tareas de reconstrucción histórica" porque "la obra misma nos interpela (anspricht)", la obra y no su contexto real originario (Gadamer, 1993, p. 49).

La continuidad o no-diferencia entre lo estético/artístico y lo real posee en Gadamer un carácter ontológico ya que la imagen o representación artística no es meramente un objeto que esté en la realidad y que remita a ella, sino que está tan vinculada a la realidad que pertenece a ella, a su ser: "La imagen (Bild) no se remite sin más a lo representado. La representación (Darstellung) permanece más bien esencialmente vinculada con lo representado, incluso pertenece (gehört) a ello" (Gadamer, 1960, p. 143). Esta es "la unidad originaria y la nodiferencia de representación y representado (Dargestelltem)" (Ibíd., p. 144). Lo fundamental es aclarar cómo se representa lo representado en la imagen artística, y la respuesta es que se representa no meramente haciendo referencia, sino que lo representado mismo está (es) en la representación. Si "la diferencia estética considera la representación como tal, separándola frente a lo representado", lo que propone Gadamer es "inseparabilidad ontológica de la imagen respecto de lo representado [...] la no diferencia entre la representación y lo representado" (Ibíd.). La representación artística ya no es un signo exterior referido a lo real representado, al objeto de-signado, puesto que eso representado está en su representación: "No es un proceso casual sino que pertenece al propio ser de lo representado [...] es un proceso ontológico (Seinsvorgang) que constituye el rango ontológico de lo representado" (Ibid., p. 145). La imagen artística "no está separada sin más de lo que representa sino que forma parte (teilhat) de su ser" (Ibid., p. 158), pertenece al ser de lo representado. Esto es lo que Gadamer denomina "valor ontológico (Seinsvalenz) de la imagen" (Ibíd., p. 139). Lo que define a la hermenéutica gadameriana es que rompe con la comprensión intelectualista de la representación para dotarla de significado ontológico: "E1 modo como algo se representa (darstellt) pertenece más bien a su propio ser" (Ibid., p. 479). Figal concluye que

una imagen, según la entiende Gadarner, no es una copia (Abbild) ni una duplicación (Verdoppelung) de algo que se pueda mantener junto a lo copiado (Abgebildete) y compararlo con él. Más bien, en una imagen está presente (präsent) lo representado; la imagen es una manifestación perteneciente a lo representado (Figal, 2007, p. 222).

Frente a la diferencia ontológica que subyace a la diferencia estética, la "esencia de la representación no es la diferencia ontológica (Seinsunterschied) entre la representación y lo representado, sino la total identificación con lo representado" (Gadamer, 1972, p. 84). De aquí deriva Gadamer que "la representación es un proceso ontológico" (Gadamer, 1960, p. 164), lo que significa que el ser mismo es representación, es decir, que el ser, contra la metafísica de la 
sustancia y con Heidegger, no es una presencia cerrada y dada en sí, sino que sigue siendo en sus representaciones. Esta hermeneutización del ser, tesis fundamental de la ontología hermenéutica de Gadamer, encuentra su mejor expresión en el modo de ser de lo estético una vez rehabilitado hermenéuticamente. Wahrheit und Methode comienza entonces con la aclaración del problema de la verdad en el arte, porque en el arte se presenta ejemplarmente el concepto de ser verdadero renovado desde esta ontología hermenéutica. Lo estético que define a la imagen artística, lejos de estar separado ontológicamente de lo real, es aquel ámbito donde lo real sigue siendo, haciéndose, como si fuera una emanación de lo real que se continúa en lo estético del arte: "El contenido propio de la imagen es ontológicamente como una emanación (Emanation) del original (Urbildes)" (Ibíd., p. 145). Esta idea neoplatónica de emanación supera el marco de la ontología griega de la sustancia y le sirve a Gadamer para fundamentar la dimensión ontológica de la imagen. La continuidad que establece Gadamer se entiende como pertenencia de lo estético, de la representación artística, al ser de lo representado. La pertenencia (Zugehörigkeit) es el concepto clave de Gadamer para la rehabilitación hermenéutica de la diferencia estética: "La pertenencia corresponde a la experiencia hermenéutica" (Ibíd., p. 466). Contra la ruptura estética, la estética de Gadamer es una estética de la pertenencia. Esta pertenencia ontológica de la imagen a lo representado, del arte a la realidad, le permite superar el primado subjetivista de la conciencia estética moderna: "La imagen es un proceso ontológico y, por ello, no puede ser concebida como objeto (Gegenstand) de una conciencia estética" (Ibid., p. 148).

\section{Conclusión: el arte como realidad trasformada en su verdad}

Falta aclarar la diferencia que Gadamer introduce en la continuidad. Se refiere al hecho de que la representación pertenece al ser de lo representado no copiándolo, no repitiéndolo, sino trasformándolo, haciéndolo crecer, aumentando su ser: "Mediante la representación lo representado experimenta un crecimiento de ser (Zuwachs an Sein)" (Gadamer, 1960, p. 145). Por eso escribe Gadamer que "está en la esencia de la emanación que lo emanado sea un exceso (Überfluß)" (Ibíd., p. 145). La representación estética que pertenece a lo real no es copia sino una trasformación que supone un crecimiento del ser de la realidad representada. Gadamer insiste en que el "carácter específico del arte de crecimiento de ser" significa una "ganancia en ser (Gewinnes an Sein) que el ente experimenta al representarse" (Gadamer, 1974, p. 128). Esto quiere decir que la representación artística supone una novedad, pues en vez de repetir el original representado dice algo no dicho sobre él: "Una imagen así no es 
una copia porque representa algo que sin ella no se representaría así. Declara (aussagt) algo sobre el original" (Gadamer, 1960, p. 145). Ahora bien, este crecimiento significa para Gadamer que en la representación artística lo real se da esencializado, en su verdad. Lo representado "experimenta un crecimiento de ser (Seinszuwachs)" en la representación, pero de tal modo que "lo representado llega en la imagen a sí mismo" (Ibíd., p. 158), o sea, a su plenitud esencial, a su verdad. Aquello nuevo que declara la imagen es por tanto la verdad. Hay entonces continuidad porque la imagen pertenece a lo real y lo real mismo se continúa en la imagen, pero hay también diferencia porque lo real se da en la representación trasformado, como plenificado o aumentado en su verdad: "El mundo que aparece en el juego de la representación (Spiel der Darstellung) no es como una copia al lado del mundo real, sino que es este mismo mundo en la acrecentada (gesteigerten) verdad de su ser" (Ibíd., p. 142). Así es como el arte puede ser la realidad trasformada en su verdad. La realidad representada en el arte es más que esa realidad sin representar: "El Aquiles homérico es más que su original" (Ibid., p. 120). Lo real representado en el arte es lo real pero depurado en su esencia, en su verdad, liberado de todo lo casual, contingente y accidental. La representación artística esencializa. En tanto es representado artísticamente, lo real se esencializa, "se libera de la particularidad (Einmaligkeit) y casualidad (Zufälligkeit) de las circunstancias (Umstände) en las que es hallado" y "con ello comienza a elevarse (erheben) hacia su esencia permanente (bleibenden Wesen) y a separarse de la casualidad de su hallazgo" (Gadamer, 1972, pp. 83s). Lo real representado en el arte queda liberado de su contingencia, reducido a su esencia, y así el arte es la realidad potenciada, trasformada representativamente en su verdad. ${ }^{5}$ En este sentido puede afirmarse con Gadamer que el arte rehabilitado hermenéuticamente equivale, como ya percibió Husserl, a una espontánea epojé y reducción fenomenológicas, que, tras desconectar el mundo concreto con todas sus posiciones contingentes, pueden reducirse a su esencia (Gadamer, 1981, p. 255). Gadamer deduce que el arte, por ser lo real trasformado en su esencia, ofrece más conocimiento porque la representación no es solo "repetición que reproduce (abbildende Wiederholung), sino conocimiento de la esencia": "Con vista al conocimiento de lo verdadero es el ser de la representación más

5 Este valor ontológico veritativo es lo que Gadamer encuentra p. e. en el retrato pictórico, que no es mera copia del retratado sino su "idealización (Idealisierung)": "La individualidad retratada en el retrato pueda estar liberada de lo casual y privado, y elevada a lo esencial de su manifestación más válida” (Gadamer, 1960, pp. 153s). Por no ser el retrato mera copia del original, sino el retratado trasformado en su verdad, esencializado, "lo que en la imagen accede al ser no estaba contenido en lo que sus conocidos ven en lo copiado", y por eso "los mejores jueces de un retrato no son los parientes más próximos ni siquiera el representado mismo" (Ibíd.). 
que el ser del material representado" (Gadamer, 1960, p. 120). Gadamer ha recuperado el destacado y peculiar poder cognoscitiva que tuvo el arte cuando verdad y esencia eran lo mismo: "Mientras se identificó conocimiento de la verdad con conocimiento de la esencia, se creyó en el poder cognoscitivo del arte" (Ibid.). Cuando se quebró esta identidad en el mundo moderno científico y se supeditó la verdad al método, se esfumó el valor cognosctivio del arte y se pasó al dominio positivista del conocimiento y la verdad por parte de la ciencia metódica.

\section{Referencias}

DERRIDA, J. "De la grammatologie". Paris: Minuit, 1967.

DI CESARE, D. "Gadamer - Ein philosophisches Porträt”. Tübingen: Mohr Siebeck, 2009.

FIGAL, G. "Wahrheit und Methode als ontologischer Entwurf. Der universale Aspekt der Hermeneutik (GW 1, 478-494)" 219-235. En: FIGAL, G. (hg.). Hans-Georg Gadamer: Wahrheit und Methode, Klassiker Auslegen. Band 30, Berlin: Akademie Verlag, 2007. GADAMER, H-G. (1958). "Zur Fragwürdigkeit des ästhetischen Bewußtseins" 9-17. Ästhetik und Poetik I. Kunst als Aussage. Gesammelte Werke (GW), Band 8, Tübingen: Mohr (Siebeck), 1993.

. (1960) "Hermeneutik I. Wahrheit und Methode. Grundzüge einer philosophischen Hermeneutik". GW, Band 1, 2. Aufl. 1990.

. (1964) "Ästhetik und Hermeneutik" 1-8. GW, Band 8.

. (1965) "Wahrheit und Methode. Vorwort zu 2. Auflage" 437-448. Hermeneutik

II. Wahrheit und Methode. Ergänzungen. Register. GW, Band 2, 2. Aufl. 1993.

. (1972) "Dichtung und Mimesis" 80-85. GW, Band 8.

. (1974) "Die Aktualität des Schönen. Kunst als Spiel, Symbol und Fest" 94$\overline{142 . G W}$, Band 8.

. (1980) "Anschauung und Anschaulichkeit" 189-205. GW, Band 8.

(1981) "Philosophie und Literatur" 240-257. GW, Band 8.

10, 1995.

. (1985a) "Die Kehre des Weges" 71-75. Hermeneutik im Rückblick. GW, Band

. (1985b) "Zwischen Phänomenologie und Dialektik" 3-23. GW, Band 2.

. (1986) "Der eine Weg Martin Heideggers" 417-430. Neuere Philosophie I:

Hegel-Husserl-Heidegger. GW, Band 3, 1987.

Band 10.

(1987) "Frühromantik, Hermeneutik, Dekonstruktivismus" 125-137. GW,

(1992) "Zur Phänomenologie von Ritual und Sprache" 400-440. GW, Band 8. . (1993) DUTT, C (hg.). "Hermeneutik. Ästhetik. Praktische Philosophie. Hans-Georg Gadamer im Gespräch”. Heidelberg: Universitätsverlag C. Winter, 1995. 
GREISCH, J. "Le cogito herméneutique. L’herméneutique philosophique et l'héritage cartésien”. Paris: J. Vrin, 2000a.

. "Le phénomène du jeu et les enjeux ontolologiques de l'herméneutique".

Revue Internationale de Philosophie, 213, pp. 447-468, $2000 \mathrm{~b}$.

GRONDIN, J. "Von Heidegger zu Gadamer. Unterwegs zur Hermeneutik”. Darmstadt: Wissenschaftliche Buchgesellschaft, 2001.

. "L'herméneutique". Paris: PUF, 2006.

HAMMERMEISTER, K. "Hans-Georg Gadamer”. München: C. H. Beck, 1999.

HEIDEGGER, M. (1935) "Einführung in die Metaphysik". Gesamtausgabe (Ga), Band 40, Frankfurt am Main: Vittorio Klostermann, 1983.

. (1935-36) "Der Ursprung des Kunstwerkes" 1-74. Holzwege, Ga 5, 1977.

. (1936-37) "Der Wille zur Macht als Kunst" 1-224. Nietzsche I, Ga 6.1, 1996.

. (1936-38) "Beiträge zur Philosophie (Vom Ereignis)". Ga 65, 1989.

. (1938) "Die Zeit des Weltbildes" 75-113. Holzwege.

. (1938-39) "Besinnung". Ga 66, 1997.

. (1951-52) "Was heisst Denken?". Ga 8, 2002.

(1953a) "Wissenschaft und Besinnung" 37-65. Vorträge und Ausätze, Ga 7, 2000.

. (1953b) "Die Frage nach der Technik" 5-36. Vorträge und Aufsätze.

(1953-54) "Aus einem Gespräch von der Sprache" 79-146. Unterwegs zur

Sprache, $G a 12,1985$.

. (1964) "Die Ende der Philosophie und die Aufgabe des Denkens" 67-90. Zur

Sache des Denkens, Ga 14, 2007.

KANT, I. (1790). “Kritik der Urteilskraft”. Hamburg: Felix Meiner Verlag, 1990.

PALMER, R. E. "Hermeneutics. Interpretation Theory in Schleiermacher, Dilthey, Heidegger and Gadamer". Evanston: Northwestern University Press, 1969.

RICOEUR, P. “Du texte à l'action. Essais d'herméneutique II”. Paris: Du Seuil, 1986.

SIMMS, K. "Hans-Georg Gadamer". London-New York: Routledge, 2015.

VEDDER, B. "Was ist Hermeneutik?. Ein Weg von der Textdeutung zur Interpretation der Wirklichkeit”. Stuttgart: Kohlhammer, 2000.

VILHAUER, M. "Gadamer's Ethics of Play. Hermeneutics and the Other". Lanham, Maryland: Lexington Books, 2010. 